\title{
Atividade antifúngica de extratos vegetais sobre o desenvolvimento de fitopatógenos ${ }^{1}$
}

\author{
Luciano dos Reis Venturoso ${ }^{2}$, Lilian Maria Arruda Bacchi², Walber Luiz Gavassoni², Lenita Aparecida Conus ${ }^{2}$, Bruno \\ Cesar Alvaro Pontim² \& Anderson Cristian Bergamin²
}

2Universidade Federal da Grande Dourados, Faculdade de Ciências Agrárias, Rodovia Dourados-Itahum km 12, Caixa Postal 533, 79804-970, Dourados-MS.

Autor para correspondência: Luciano dos Reis Venturoso (luck_rv@ hotmail.com)

Data de chegada: 10/04/2010. Aceito para publicação em: 17/01/2011.

\section{RESUMO}

Venturoso, L.R.; Bacchi, L.M.A.; Gavassoni, W.L. Atividade antifúngica de extratos vegetais sobre o desenvolvimento de fitopatógenos. Summa Phytopathologica, v.37, n.1, p.18-23, 2011.

A formação de uma consciência ecológica e a busca pela preservação do meio ambiente tem gerado a necessidade de testar produtos naturais, visando um controle alternativo de fitopatógenos. Desta forma, objetivou-se avaliar o potencial de dez extratos aquosos sobre o desenvolvimento in vitro de fungos fitopatogênicos. Foram conduzidos seis ensaios experimentais em delineamento inteiramente casualizado, com 11 tratamentos e 10 repetições para cada ensaio. Os tratamentos constaram dos extratos bruto aquosos de alho, arruda, canela, cravo-da-índia, cavalinha, eucalipto, hortelã, jabuticaba, melão de são caetano e nim na concentração de $20 \%$, mais a testemunha (somente BDA). Os ensaios foram realizados com os fungos Aspergillus sp., Penicillium sp., Cercospora kikuchii, Colletotrichum sp., Fusarium solani e Phomopsis sp. Os extratos foram filtrados em papel wathman $\mathrm{n}^{\circ}$ 1 , colocados em banho maria a $65^{\circ} \mathrm{C}$, durante 1 hora, incorporados em meio BDA e após vertido em placas de Petri, transferiu-se discos de micélio dos patógenos ( $0,3 \mathrm{~cm}$ de diâmetro). Foi analisado o crescimento micelial da colônia, a porcentagem de inibição e a taxa de crescimento dos fungos. Observou-se que os meios de cultura contendo os extratos de cravo-da-índia, alho e canela apresentaram maior atividade antifúngica sobre os fitopatógenos, quando comparados aos demais extratos utilizados, destacando o extrato de cravo-da-índia, que inibiu completamente o desenvolvimento de todos os fitopatógenos testados.

Palavras-chave adicionais: crescimento micelial, plantas medicinais e controle alternativo.

\section{ABSTRACT}

Venturoso, L.R.; Bacchi, L.M.A.; Gavassoni, W.L. Antifungal activity of plant extracts on the development of plant pathogens. Summa Phytopathologica, v.37, n.1, p.18-23, 2011.

The formation of an ecological conscience and the search for the preservation of the environment have generated the need to test natural products, targeting an alternative control of plant pathogens. In this way aimed at evaluating the potential of ten aqueous extracts on the in vitro development of phytopathogenic fungi. Were conducted six experimental trials in a completely randomized design with 11 treatments and 10 replications for each assay. The treatments consisted of crude aqueous extracts of garlic, rue, cinnamon, clove, horsetail, eucalyptus, mint, jabuticaba, melon-of-são-caetano and neem in the concentration of $20 \%$, more the control treatment (only PDA). The trials were carried out with the fungus Aspergillus sp.,
Penicillium sp., Cercospora kikuchii, Colletotrichum sp., Fusarium solani and Phomopsis sp. The extracts were filtered in paper wathman $\mathrm{n}^{\circ} 1$, put in the water bath at $65^{\circ} \mathrm{C}$ for 1 hour, incorporated in PDA medium and after poured into Petri dishes, transferred to mycelial discs of pathogens $(0.3 \mathrm{~cm}$ of diameter $)$. Was determined the mycelial growth of the colony, the percentage of inhibition and the rate of growth of fungi. It was observed that the PDA medium containing the extracts of clove, garlic and cinnamon showed most antifungal activity on the plant pathogens, when compared to other extracts used, highlighting for the extract of clove, which inhibited the development of all pathogens tested.

Palavras-chave adicionais: mycelial growth, medicinal plant, alternative control

Nas últimas décadas a exploração da atividade de compostos secundários de plantas tem se tornado uma alternativa no controle de fitopatógenos com potencial ecológico para substituir o emprego de produtos sintéticos, por meio da utilização de subprodutos de plantas medicinais como extrato bruto e óleo essencial, uma vez que apresentam, em sua composição, substâncias com propriedades fungicidas e/ou fungitóxicas (15). Esses compostos possuem a vantagem de serem geralmente menos prejudiciais ao homem e ao meio ambiente, de menores custos, facilmente disponíveis aos agricultores, e em alguns casos podem inclusive superar os produtos sintéticos em sua ação antimicrobiana (22).

Devido à grande riqueza química das plantas medicinais que possuem princípios ativos microbiocidas, elas se tornam fontes potenciais de moléculas que podem ser empregadas na defesa de plantas contra fitopatógenos (18). Esses compostos pertencem a várias classes distintas de substâncias químicas, como alcalóides, terpenos, lignanas, flavonóides, cumarinas, benzenóides, quinonas, xantonas, lactonas e esteróides, entre outras (10).

A diversidade de substâncias ativas em plantas medicinais tem motivado o desenvolvimento de pesquisas envolvendo o uso de extratos 
vegetais, no intuito de explorar suas propriedades fungitóxicas (12). $\mathrm{Na}$ literatura tem-se verificado o registro da eficiência de extratos vegetais, obtidos de diversas espécies botânicas, como é o caso da arruda, melão de são caetano, eucalipto (8), cavalinha, hortelã (19), alho, canela (24), cravo-da-índia (1), jabuticaba (23) e nim (7), na promoção da inibição do desenvolvimento de vários fitopatógenos de natureza fúngica. Considera-se ainda, que a diversidade dessas substâncias poderia possibilitar a utilização direta pelo produtor, por meio do cultivo da planta possuidora dos compostos secundários, preparo e aplicação direta do extrato nas culturas comerciais (8).

Trabalhos desenvolvidos com extrato bruto e óleo essencial, obtidos a partir de plantas medicinais, têm indicado o potencial das mesmas no controle de fitopatógenos (9), tanto por sua ação fungitóxica direta, inibindo o crescimento micelial e a germinação de esporos, quanto pela indução de fitoalexinas $(14,21)$.

Existem relatos da atividade antifúngica direta de extratos aquosos e óleos essenciais obtidos a partir de plantas contra uma ampla gama de fungos, como Altermaria alternata (Fr.) Kiessler, Macrophomina phaseolina (Tassi) Goidanich (5), Colletotrichum gloeosporioides (Penz.) Penz. \& Sac. (8), Didymella bryoniae (Auersw.) Rehm (11), Fusarium moniliforme Sheldon (16) e Phytophthora infestans (Mont.) de Bary (25).

A formação de uma consciência comum sobre a necessidade de se preservar o meio ambiente tem gerado a necessidade de testar produtos naturais, visando um controle alternativo de fitopatógenos. Diante do contexto, objetivou-se avaliar a atividade antifúngica dos extratos bruto aquosos de alho, arruda, canela, cravoda-índia, cavalinha, eucalipto, hortelã, jabuticaba, melão de são caetano e nim sobre o desenvolvimento micelial dos fungos, Aspergillus sp., Penicillium sp., Colletotrichum sp., Phomopsis sp., Fusarium solani (Snyd \& Hans) e Cercospora kikuchii (Mats. \& Tomoy.) Gardner.

\section{MATERIAL E MÉTODOS}

Os ensaios foram conduzidos no Laboratório de Fitopatologia da Universidade Federal da Grande Dourados (UFGD), no período de novembro de 2007 a abril de 2008. Os extratos vegetais foram preparados no próprio laboratório, a partir de plantas coletadas junto ao Horto de Plantas Medicinais da UFGD e de produtores locais.

Adotou-se o delineamento experimental inteiramente casualizado, com 11 tratamentos e 10 repetições, para cada ensaio. Os extratos foram obtidos a partir de bulbos de alho (Allium sativum L.), casca de canela (Cinnamomum zeylanicum Breym), botão floral de cravo-da-índia (Syzygium aromaticum L.), folhas de eucalipto (Eucalyptus citriodora Hooker M.), casca do fruto de jabuticaba (Myrcia cauliflora Berg), sementes de nim (Azadirachta indica A. Juss.), e parte aérea de arruda (Ruta graveolens L.), cavalinha (Equisetum sp.), hortelã (Mentha piperita L.) e melão de são caetano (Momordica charantia L.), mais a testemunha, que constou apenas do meio de cultura Batata-Dextrose-Agar (BDA). Utilizou-se para cada ensaio experimental um fitopatógeno, sendo esses, Aspergillus sp., Penicillium sp., C. kikuchii, Colletotrichum sp., F. solani e Phomopsis sp.

Os fungos Aspergillus sp. e Penicillium sp. foram isolados a partir de sementes de soja, no Laboratório de Fitopatologia da UFGD, e os demais fungos foram fornecidos pelo Centro Nacional de Pesquisa de Soja - Embrapa Soja.
Para obtenção dos extratos vegetais, foram coletadas $20 \mathrm{~g}$ do material vegetal e trituradas em liquidificador com $100 \mathrm{ml}$ de água destilada. O material foi filtrado em papel wathman $n^{\circ} 1$ e colocado em banho maria a $65^{\circ} \mathrm{C}$ por um período de 1 hora. Em seguida os extratos aquosos foram homogeneizados ao meio BDA fundente, de modo a obter uma concentração de $20 \%$, e vertidos em placas de Petri. Posteriormente à solidificação do BDA, foram transferidos no centro das placas, discos de $0,3 \mathrm{~cm}$ de diâmetro do micélio dos fitopatógenos. Os isolados fúngicos utilizados na pesquisa foram retirados a partir de culturas puras com sete dias de idade em meio BDA.

As placas de Petri foram incubadas em câmara BOD a uma temperatura de $25^{\circ} \mathrm{C}$, com fotoperíodo de 12 horas. As avaliações foram realizadas a cada três dias, perdurando até o momento em que as colônias atingiram $3 / 4$ da superfície do meio de cultura (22).

Para avaliação do crescimento micelial das colônias fúngicas foram realizadas medições do crescimento radial da colônia em dois eixos ortogonais, descartando-se o disco repicado da colônia pura, sendo posteriormente calculada uma média. A porcentagem de inibição do crescimento (PIC) foi obtida por meio da fórmula: $\mathrm{PIC}=[($ diâmetro da testemunha - diâmetro do tratamento $) /$ diâmetro da testemunha] x 100, para cada extrato em relação à testemunha. A taxa de crescimento dos fitopatógenos foi mensurada conforme Benício et al. (4), onde os dados foram plotados para obtenção de uma equação de regressão linear simples $(y=a+b x)$, sendo $(x)$ os dias de incubação, (y) o diâmetro final da colônia, (a) o diâmetro inicial da colônia e (b) a taxa de crescimento micelial, determinada pelo coeficiente de regressão.

Os dados foram transformados em $V_{\mathrm{x}}+1$, submetidos a análise de variância com auxílio do SISVAR, e as médias comparadas pelo teste de agrupamento de Scott-Knott a 5\% de probabilidade.

\section{RESULTADOS E DISCUSSÃO}

O resultado da análise de variância indicou diferenças na atividade antifúngica dos extratos vegetais sobre os fitopatógenos utilizados no estudo.

Com relação ao crescimento micelial, foi constatada atividade antifúngica sobre todos os fitopatógenos estudados, apenas com a utilização dos extratos aquosos de cravo-da-índia, alho e canela. A inibição proporcionada pelos extratos foi observada a partir do terceiro dia de incubação e persistiu até o final das avaliações (Figura 1).

Foi verificado que Aspergillus sp., incubado em meio de cultura com adição do extrato de cravo-da-índia não apresentou crescimento micelial. Os resultados evidenciaram maior atividade antifúngica do extrato quando comparado aos demais, com exceção ao terceiro dia de incubação, onde o mesmo assemelhou-se ao extrato de alho (Figura 1A). Também em estudos com extrato de cravo-da-índia, Belém (3) verificou que o produto inibiu tanto a germinação de esporos, como o crescimento micelial de A. flavus e de A. niger.

Viegas et al. (24), analisando a toxidade de óleos essenciais, verificaram maior inibição do desenvolvimento micelial de A. flavus com o emprego dos óleos de bulbilho de alho e principalmente, de casca de canela. No estudo, o extrato de alho reduziu significativamente o crescimento de Aspergillus sp., entretanto, o extrato realizado a partir de casca de canela, assim como o extrato de hortelã apresentaram atividade antifúngica intermediária. Os demais extratos não diferiram da testemunha. Wilson et al. (26) também encontraram propriedades 

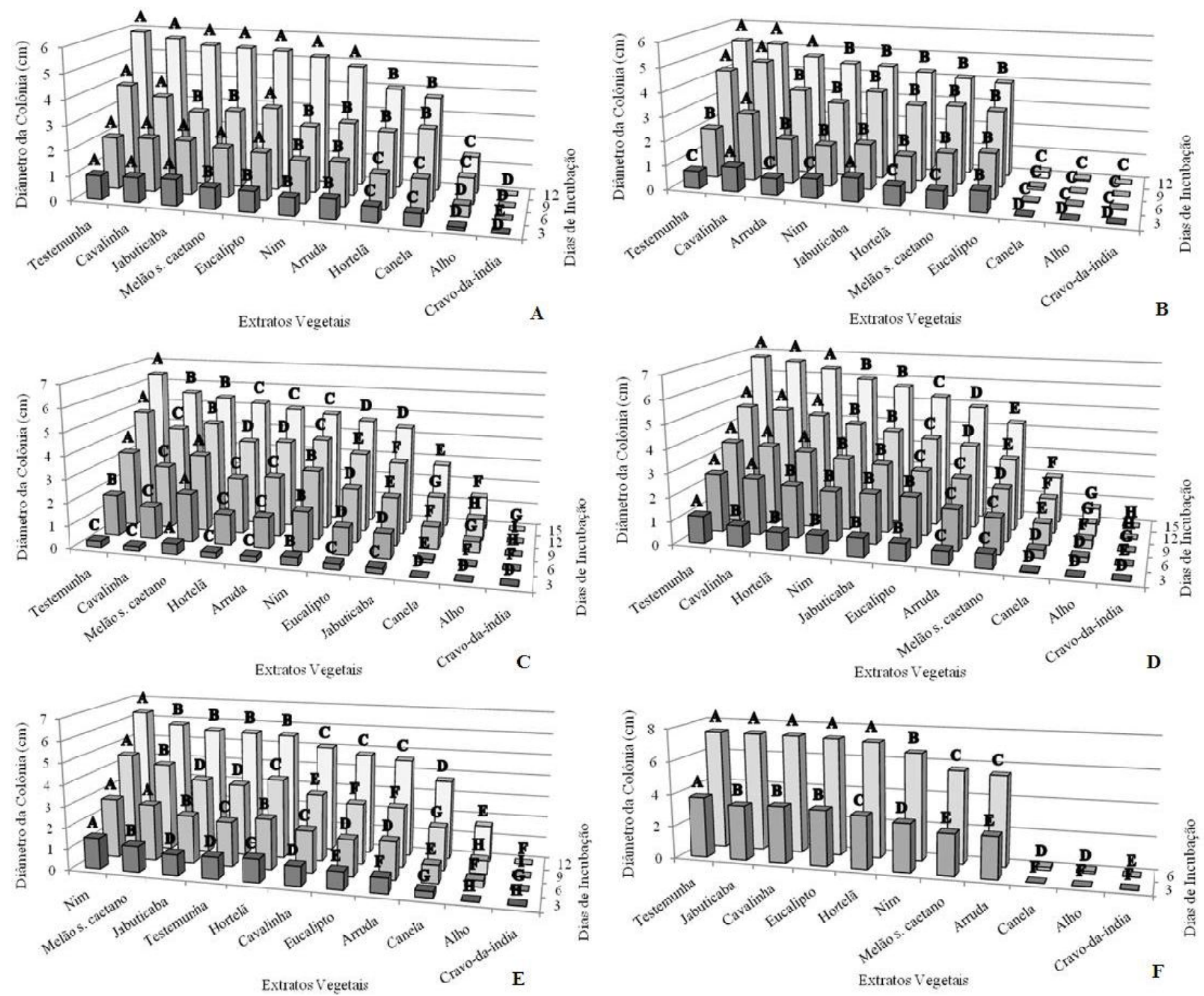

Figura 1. Crescimento micelial de fungos fitopatogênicos submetidos a diferentes tratamentos com extratos vegetais. (A) Aspergillus sp., (B) Penicillium sp., (C) Colletotrichum sp., (D) Cercospora kikuchii, (E) Fusarium solani e (F) Phomopsis sp. Dourados - MS, 2008. Médias seguidas pela mesma letra na linha, não diferem entre si pelo teste de agrupamento de Scott-Knott a 5\%.

antifúngicas no extrato de hortelã, demonstrando potencial no controle de Botrytis cinerea Persex Fries.

Os extratos aquosos de cravo-da-índia, alho e canela demonstraram em todas as avaliações, significativa atividade antifúngica sobre o crescimento micelial de Penicillium sp., sendo superiores aos demais extratos (Figura 1B).

Pode ser notado, aos três dias de incubação, maior crescimento de Penicillium sp. nos tratamentos contendo extrato de cavalinha e jabuticaba. Estes extratos proporcionaram maior crescimento do fungo até o sexto dia de incubação, pressupondo que possam existir substâncias que estimulem e/ou favoreçam inicialmente o crescimento deste patógeno. Entretanto, aos doze dias de incubação constatou-se que os extratos de cavalinha e de arruda não diferiram do tratamento controle, enquanto os extratos de eucalipto, melão de são caetano, hortelã, jabuticaba e nim reduziram significativamente o desenvolvimento micelial do fungo em 24,5,
22,2, 18,8,15,6 e 14,8\%, respectivamente.

Colletotrichum sp. apresentou desenvolvimento mais lento, estendendo as análises até os quinze dias de incubação. Constatouse ao final das avaliações, com base no diâmetro da colônia fúngica, que todos os extratos vegetais testados no estudo apresentaram atividade antifúngica, em maior ou menor intensidade (Figura 1C).

Não foi verificado crescimento micelial de Colletotrichum sp. aos quinze dias de incubação, quando este foi submetido ao extrato aquoso de cravo-da-índia. Trabalhando com o fungo $C$. gloeosporioides, Rozwalka et al. (19) notaram que não houve crescimento micelial do fungo com a utilização do extrato aquoso de cravo na concentração de $10 \%$.

$\mathrm{O}$ extrato de alho reduziu significativamente o crescimento micelial em relação aos demais tratamentos, enquanto que o meio de cultura contendo extrato de canela apresentou atividade antifúngica, porém em menor intensidade. Ribeiro \& Bedendo (17), 
avaliando o efeito inibitório de extratos vegetais sobre $C$. gloeosporioides, verificaram que o extrato de alho apresentou propriedades fungitóxicas, inibindo o crescimento micelial do patógeno.

O fungo C. kikuchii também apresentou crescimento lento no decorrer dos dias de incubação (Figura 1D). Notou-se menor crescimento micelial de $C$. kikuchii, com a adição ao meio de cultura, dos extratos aquosos de cravo-da-índia, alho e canela. O extrato de cravo-da-índia suprimiu o crescimento do fungo, apresentando diferença significativa quando comparado aos demais extratos vegetais testados. Tanto o extrato de alho quanto o de canela suprimiram o crescimento do patógeno até o terceiro dia de incubação, entretanto, a persistência da fungitoxidade destes extratos não se manteve ao longo do período de incubação, sendo constatado com a utilização do alho crescimento da ordem de $0,72 \mathrm{~cm}$, provocando diferenças em relação ao extrato de canela, onde o micélio fúngico alcançou $1,98 \mathrm{~cm}$.

No ensaio realizado com $F$. solani foi verificado, em todos os dias de incubação, maior crescimento do patógeno quando submetido ao extrato de nim, resultando ao final do período de incubação, crescimento micelial de $13,6 \%$ superior em relação à testemunha (Figura 1E). Este favorecimento no crescimento de fitopatógenos também é relatado por Amaral \& Bara (1). Os autores constataram com a utilização da planta Albizzia lebbeck (L.), que F. solani e Sclerotium rolfsii Sacc. tiveram seu crescimento micelial estimulado, pressupondo assim, a existência de alguma substância ativadora deste crescimento no extrato proveniente desta planta.

Govindachari et al. (13) afirmam que o efeito do nim é variável e dependente do patógeno alvo. Os autores verificaram que a azadiractina, principal constituinte químico encontrado nas sementes, não interferiu no crescimento de Drechslera oryzae (Breda de Haan) Subram \& Jain, Fusarium oxysporum Schlecht. e Alternaria tenuis Nees. Confirmando essa variação, relata-se a ineficiência do extrato de nim sobre Phytophthora capsici Leonian (2), e a inibição do crescimento de A. alternata e M. phaseolina, nas concentrações de 0,5 e $1 \%$ (5).

Não se verificou crescimento micelial de $F$. solani no terceiro dia de incubação, com a utilização dos extratos de alho e cravo-daíndia, sendo ambos superiores aos demais tratamentos. No entanto, apenas o extrato de cravo apresentou atividade fungistática em relação ao patógeno, ao final das avaliações.

Pode ser verificada ainda, a presença de compostos com atividade antifúngica na utilização dos extratos de canela, arruda, eucalipto e cavalinha, sendo o primeiro superior aos demais. Corroborando com os resultados, constatam-se que os extratos obtidos das plantas de eucalipto (11) e arruda (22) apresentaram-se eficientes na inibição do crescimento de $D$. bryoniae e $S$. rolfsii, respectivamente.

Observam-se divergências nos trabalhos que visam avaliar a atividade antifúngica de extratos vegetais sobre o crescimento de fitopatógenos, mesmo àqueles que estudam a mesma planta. A diferença nestes resultados pode estar associada às condições edafoclimáticas em que as plantas foram cultivadas, ou ainda, à época do ano em que a mesma foi coletada. Di Stasi (10) afirma ainda que a concentração de princípios ativos não se apresenta uniforme no decorrer do ciclo da planta, podendo apresentar variações conforme as condições de cultivo, a colheita e o processamento do material vegetal.

Pode ser observado na Figura 1F, que Phomopsis sp. apresentou rápido crescimento, finalizando as avaliações ao sexto dia de incubação. No terceiro dia pode ser constatado que todos os extratos apresentavam atividade antifúngica, não sendo observado crescimento do fungo com o uso de canela, alho e cravo-da-índia.

Ao final das análises não foram verificadas diferenças no desempenho dos extratos de jabuticaba, cavalinha, eucalipto e hortelã em relação ao tratamento controle. Os extratos de melão de são caetano e arruda proporcionaram redução de 23,2 e $25,3 \%$, respectivamente, do crescimento do patógeno. O menor desenvolvimento de Phomopsis sp. foi alcançado com o uso de cravo-da-índia, seguido dos extratos de alho e canela.

Com base no crescimento micelial dos fitopatógenos testados no estudo, foram evidenciadas em várias leituras, alterações na proporção do crescimento das colônias fúngicas com o decorrer do período de incubação, provocando em dados momentos maior ou menor crescimento do fungo. Pode-se citar como exemplo o extrato de jabuticaba com Aspergillus sp., o extrato de cavalinha com Penicillium sp., e o extrato de melão de são caetano com o fungo Colletotrichum sp. Este fato pode estar associado à presença de compostos que possuem tanto atividades antifúngicas, como também compostos que estimulam o crescimento dos patógenos. A quantidade e a longevidade destes compostos, assim como a relação existente entre estes, podem resultar em determinados momentos, em maior ou menor inibição dos fitopatógenos. Resultados semelhantes são relatados por Rozwalka et al. (19).

Não foi observado, com a utilização do extrato aquoso de cravoda-índia, crescimento micelial de nenhum dos fitopatógenos estudados. No intuito de verificar se o extrato havia apresentado ação fungicida sobre os fungos, foram retirados os discos de micélio do meio de cultura contendo o cravo-da-índia e adicionados em BDA puro, sendo observado a partir do quinto e sexto dia de incubação que os fungos voltavam a crescer, evidenciando desta forma, que o extrato apresentou atividade fungistática.

Considerou-se alta atividade antifúngica dos extratos aquosos, quando os mesmos proporcionaram inibição igual ou superior a $50 \%$. Em relação à característica porcentagem de inibição do crescimento dos fitopatógenos, foi verificada inibição superior a $50 \%$ do crescimento micelial de todos os fungos quando se utilizou os extratos de cravo-da-índia e alho. O extrato de canela proporcionou inibição superior a $50 \%$ sobre C. kikuchii, Colletotrichum sp., Penicillium sp. e Phomopsis sp. (Tabela 1). Nota-se que o extrato realizado a partir de cravo-da-índia proporcionou em todos os bioensaios, $100 \%$ de inibição sobre os patógenos. Estes resultados estão de acordo com os relatados por Roswalka et al. (19), que constataram $100 \%$ de inibição do crescimento de Glomerella cingulata (Ston.) Spauld \& Schrenk e C. gloeosporioides, quando estes foram submetidos ao extrato aquoso de cravo-da-índia. Entretanto, Bilgrami et al. (6) avaliando a inibição do crescimento de $A$. flavus, verificaram que a maior inibição no crescimento do fungo foi obtida quando se utilizou o extrato de alho $(61,9 \%)$, obtendo resultados superiores quando comparado ao eugenol, principal composto presente no cravo-daíndia.

Com exceção aos extratos de cravo-da-índia, alho e canela, os demais extratos, apesar de evidenciarem atividade antifúngica, não apresentaram resultados satisfatórios. Pode-se citar o uso do extrato de melão de são de caetano, alcançando $36,6 \%$ de inibição para $C$. kikuchii e estimulando em $4,3 \%$ o crescimento de $F$. solani. Celoto et al. (8) verificaram que dos 20 extratos avaliados somente aqueles provenientes de espirradeira, eucalipto e melão de são caetano 
Tabela 1. Inibição do crescimento (\%) micelial de fitopatógenos submetidos a diferentes tratamentos com extratos vegetais. Dourados, MS, 2008.

\begin{tabular}{|c|c|c|c|c|c|c|}
\hline Extratos Aquosos & \multicolumn{5}{|c|}{ Fungos Fitopatogênicos } & Phomopsis \\
\hline Cravo & $100,0 \mathrm{a}$ & $100,0 \mathrm{a}$ & $100,0 \mathrm{a}$ & $100,0 \mathrm{a}$ & $100,0 \mathrm{a}$ & $100,0 \mathrm{a}$ \\
\hline Alho & $75,2 \mathrm{a}$ & 89,4 a & $77,7 \mathrm{~b}$ & $69,9 \mathrm{~b}$ & 98,9 a & 98,2 a \\
\hline Canela & $36,5 \mathrm{~b}$ & $70,8 \mathrm{~b}$ & $56,3 \mathrm{c}$ & $33,5 \mathrm{c}$ & 95,1 a & 97,4 a \\
\hline Hortelã & $31,9 \mathrm{~b}$ & $6,0 \mathrm{~g}$ & $18,3 \mathrm{f}$ & $0,8 \mathrm{f}$ & $18,9 \mathrm{~b}$ & $2,9 \mathrm{~d}$ \\
\hline $\mathrm{Nim}$ & $12,2 \mathrm{c}$ & $12,1 \mathrm{f}$ & $24,0 \mathrm{e}$ & $-13,6 \mathrm{~g} *$ & $14,8 \mathrm{c}$ & $10,4 \mathrm{c}$ \\
\hline Eucalipto & $9,2 \mathrm{c}$ & $21,7 \mathrm{e}$ & $27,5 \mathrm{~d}$ & $14,6 \mathrm{~d}$ & $24,5 \mathrm{~b}$ & $1,4 \mathrm{e}$ \\
\hline Melão SC & $8,3 \mathrm{c}$ & $36,6 \mathrm{c}$ & $15,4 \mathrm{f}$ & $-4,3 \mathrm{~g} *$ & $22,3 \mathrm{~b}$ & $23,2 \mathrm{~b}$ \\
\hline Jabuticaba & $7,5 \mathrm{c}$ & $16,1 \mathrm{f}$ & $31,1 \mathrm{~d}$ & $-0,4 \mathrm{f}^{*}$ & $15,6 \mathrm{~b}$ & $0,1 \mathrm{e}$ \\
\hline Cavalinha & $3,8 \mathrm{c}$ & $2,1 \mathrm{~h}$ & $13,0 \mathrm{f}$ & $9,7 \mathrm{e}$ & $1,3 \mathrm{~d}$ & $0,5 \mathrm{e}$ \\
\hline
\end{tabular}

Médias seguidas pela mesma letra na coluna, não diferem entre si pelo teste de agrupamento de Scott-Knott a 5\% de probabilidade. * Estímulo do crescimento micelial do patógeno.

Tabela 2. Taxa de crescimento micelial (cm/dia) de fungos fitopatogênicos submetidos a diferentes extratos aquosos. Dourados, MS, 2008.

\begin{tabular}{|c|c|c|c|c|c|c|}
\hline Extratos Aquosos & \multicolumn{5}{|c|}{ Fungos Fitopatogênicos } & Phomopsis \\
\hline Testemunha & 0,49 a & 0,45 a & 0,43 a & $0,47 \mathrm{~b}$ & $0,44 \mathrm{a}$ & $1,23 \mathrm{a}$ \\
\hline Cavalinha & 0,47 a & $0,44 \mathrm{a}$ & $0,37 \mathrm{~b}$ & $0,42 \mathrm{c}$ & $0,43 \mathrm{a}$ & $1,23 \mathrm{a}$ \\
\hline Jabuticaba & 0,46 a & $0,38 \mathrm{~b}$ & $0,29 \mathrm{~d}$ & $0,47 \mathrm{~b}$ & $0,37 \mathrm{~b}$ & $1,23 \mathrm{a}$ \\
\hline Eucalipto & $0,45 \mathrm{a}$ & $0,35 \mathrm{c}$ & $0,31 \mathrm{~d}$ & $0,40 \mathrm{c}$ & $0,33 \mathrm{~b}$ & $1,21 \mathrm{a}$ \\
\hline Nim & 0,43 a & $0,40 \mathrm{~b}$ & $0,32 \mathrm{c}$ & $0,53 \mathrm{a}$ & $0,38 \mathrm{~b}$ & $1,11 \mathrm{~b}$ \\
\hline Arruda & $0,40 \mathrm{a}$ & $0,33 \mathrm{~d}$ & $0,34 \mathrm{c}$ & $0,39 \mathrm{c}$ & 0,39 a & $0,92 \mathrm{c}$ \\
\hline Hortelã & $0,34 \mathrm{~b}$ & 0,43 a & $0,35 \mathrm{c}$ & $0,46 \mathrm{~b}$ & $0,36 \mathrm{~b}$ & $1,20 \mathrm{a}$ \\
\hline Canela & $0,31 \mathrm{~b}$ & $0,13 \mathrm{f}$ & $0,19 \mathrm{e}$ & $0,31 \mathrm{~d}$ & $0,02 \mathrm{c}$ & $0,03 \mathrm{~d}$ \\
\hline Alho & $0,12 \mathrm{c}$ & $0,05 \mathrm{~g}$ & $0,10 \mathrm{f}$ & $0,14 \mathrm{e}$ & $0,01 \mathrm{c}$ & $0,02 \mathrm{~d}$ \\
\hline
\end{tabular}

Médias seguidas pela mesma letra na coluna, não diferem entre si pelo teste de agrupamento de Scott-Knott a 5\% de probabilidade.

obtiveram porcentagem de inibição superior a $50 \%$ no controle de $C$. gloeosporioides.

O extrato aquoso de eucalipto utilizado nesta pesquisa foi realizado a partir de folhas da espécie E. citriodora, o que pode explicar a baixa atividade antifúngica do extrato, pois Salgado et al. (20), que testaram o potencial fungitóxico de E. urophylla, E. citriodora e E. camaldulensis, verificaram maior fungitoxidade de E. urophylla, atribuindo a este fato, a presença do composto globulol, inexistente nos demais.

Pode ser observado por meio da taxa de crescimento micelial, que Phomopsis sp. realmente apresenta rápido crescimento. Enquanto os demais fungos apresentaram no tratamento controle taxas de crescimento similares, constatou-se para Phomopsis sp. taxas quase três vezes maiores (Tabela 2). Destaca-se a ação dos extratos, de cravo-da-índia frente a todos patógenos estudados, do extrato de alho frente aos fungos C. kikuchii, Colletotrichum sp., Penicillium sp. e Phomopsis sp. e do extrato de canela com relação aos dois últimos, que permitiram aos patógenos taxa de crescimento igual ou inferior a $0,1 \mathrm{~cm} /$ dia.
A efetividade da ação antifúngica sobre o desenvolvimento dos fitopatógenos in vitro, evidenciou que os compostos presentes nas plantas utilizadas no estudo, na forma de extratos aquosos, apresentam-se como potenciais no controle alternativo dos fungos fitopatogênicos. Além dos resultados promissores verificados com os extratos de alho, canela e cravo-da-índia sobre todos os fitopatógenos, pode-se destacar também a atividade antifúngica de outros extratos frente a fungos específicos, como o extrato de hortelã sobre Aspergillus sp., os extratos de jabuticaba e eucalipto sobre Colletotrichum sp. e o extrato de melão de são caetano sobre $C$. kikuchii.

O extrato de cravo-da-índia apresenta atividade fungistática sobre o desenvolvimento de Aspergillus sp., Penicillium sp., Colletotrichum sp., Fusarium solani, Cercospora kikuchii e Phomopsis sp., sendo uma promissora alternativa no controle dos mesmos.

$\mathrm{O}$ extrato aquoso de alho apresenta alta atividade antifúngica sobre todos os fitopatógenos estudados.

O extrato de canela proporciona fungitoxidade sobre Cercospora kikuchii, Colletotrichum sp., Penicillium sp. e Phomopsis sp. 


\section{AGRADECIMENTOS}

A CAPES pela concessão da bolsa e a Embrapa Soja pelos isolados fúngicos fornecidos.

\section{REFERÊNCIAS BIBLIOGRÁFICAS}

1. Amaral, M.F.Z.J.; Bara, M.T.F. Avaliação da atividade antifúngica de extratos de plantas sobre o crescimento de fitopatógenos. Revista Eletrônica de Farmácia, Goiânia, v.2, n.2, p.5-8, 2005.

2. Anandaraj, M.; Leela, N.K. Toxic effect of some plant extracts on Phytophthora capsici, the root rot pathogen of black pepper. Indian Phytopathology, New Delhi, v.49, n.2, p. 181-184, 1996.

3. Belém, L.F. Efeitos de fungicidas químicos e de produtos vegetais no desenvolvimento in vitro de fungos que afetam sementes de feijão (Phaseolus vulgaris L.) durante o armazenamento. 1997. 66p. Dissertação (Mestrado em Produção Vegetal) - Universidade Federal da Paraíba, Areia.

4. Benicio, V.; Araújo, E.; Souto, F.M.; Benicio, M.J.; Felismino, D.C. Identificação e características culturais de espécies do gênero Aspergillus isoladas de sementes de feijão no Estado da Paraíba. Fitopatologia Brasileira, Brasília, v.28, n.2, p.180-183, 2003.

5. Bhutta, A.R.; Bhatti, M.H.R.; Iftikhar, A. Effect of seed diffusates on growth on seed-borne fungi of sunflower. Helia, Novi Sad, v.22, n.31, p.143-149, 1999.

6. Bilgrami, K.S.; Sinha, K.K.; Sinha, A.K. Inhibition of aflatoxin production and growth of Aspergillus flavus by eugenol and onion and garlic extracts. Indian Journal of Medical Research, New Delhi, v.96, p.171-175, 1992.

7. Carneiro, S.M.T.P.G.; Pignoni, E.; Gomes, J.C. Efeito do nim (Azadirachta indica A. Juss.) no controle da mancha angular do feijoeiro. Revista Brasileira de Plantas Medicinais, Botucatu, v.10, n.3, p.6-10, 2008.

8. Celoto, M.I.B.; Papa, M.F.S.; Sacramento, L.V.S.; Celoto, F.J. Atividade antifúngica de extratos de plantas a Colletotrichum gloeosporioides. Acta Scientiarum, Maringá, v.30, n.1, p.1-5, 2008.

9. Cunico, M.M.; Miguel, O.G.; Miguel, M.D.; Carvalho, J.L.S.; Peitz C.; Auer, C.G.; Gricoletti Junior, A. Estudo da atividade antifúngica de Ottonia martiana Miq., Piperaceae: um teste in vivo. Visão Acadêmica, Curitiba, v.4, n.2, p.77-82, 2003.

10. Di Stasi, L.C. Química de produtos naturais: principais constituintes ativos. In: Di Stasi, L.C. (Ed.). Plantas medicinais: arte e ciência. Um guia de estudos multidisciplinar. São Paulo: Universidade Paulista, 1996. p.109-127.

11. Fiori, A.C.G.; Schwan-Estrada, K.R.F.; Stangarlin, J.R.; Vida, J.B.; Scapim, C.A.; Cruz, M.E.S.; Pascholati, S.F. Antifungal activity of leaf extracts and essencial oils of some medicinal plants against Didymella bryoniae. Journal of Phytopathology, Berlin, v.148, p.483-487, 2000.

12. Franzener, G.; Stangarlin, J.R.; Schwan-Estrada, K.R.F.; Cruz, M.E.S. Atividade antifúngica e indução de resistência em trigo a Bipolaris sorokiniana por Artemisia camphorata. Acta Scienti- arum, Maringá, v.25, n.2, p.503-507, 2003.

13. Govindachari, T.R.; Suresh, G.; Gopalakrishnan, G.; Banumathy, B.; Masilamani, S. Identification of antifungal compounds from the seed oil of Azadirachta indica. Phytoparasitica, New York, v.26, n.2, p.1-8, 1998 .

14. Lyon, G.D.; Reglinski, T.; Newton, A.C. Novel disease control compounds: the potential to "immunize" plants against infection. Plant Pathology, Bangor, v.44, p.407-427, 1995.

15. Matos, F.J.A. As plantas da farmácia viva. Fortaleza: Universidade Federal do Ceará, 1997. v.1, 57p.

16. Owolade, O.F.; Amusa, A.N.; Osikanlu, Y.O.Q. Efficacy of certain indigenous plant extracts against seed-borne infection of Fusarium moniliforme on maize (Zea mays L.) in south western Nigeria. Cereal Research Communications, Szeged, v.28, p.323$327,2000$.

17. Ribeiro, L.F.; Bedendo, I.P. Efeito inibitório de extratos vegetais sobre Colletotrichum gloeosporioides - agente causal da podridão de frutos de mamoeiro. Scientia Agrícola, Piracicaba, v.56, n.4, p.1267-1271, 1999 .

18. Rodrigues, E.; Schwan-Estrada, K.R.F.; Stangarlin, J.R.; Cruz, M.E.S.; Fiori-Tutida, A.C.G. Avaliação da atividade antifúngica de extratos de gengibre e eucalipto in vitro e em fibras de bananeira infectadas com Helminthosporium sp. Acta Scientiarum, Maringá, v.28, n.1, p.123-127, 2006.

19. Rozwalka, L.C.; Lima, M.L.R.Z.C.; Mio, L.L.M.; Nakashima, T. Extratos, decoctos e óleos essenciais de plantas medicinais e aromáticas na inibição de Glomerella cingulata e Colletotrichum gloeosporioides de frutos de goiaba. Ciência Rural, Santa Maria, v.38, n.2, p.301-307, 2008.

20. Salgado, A.P.S.P.; Cardoso, M.G.; Souza, P.E.; Souza, J.A.; Abreu, C.M.; Pinto, J.E.B.P. Avaliação da atividade fungitóxica de óleos essenciais de folhas de Eucalyptus sobre Fusarium oxysporum, Botrytis cinerea e Bipolaris sorokiniana. Ciência e Agrotecnologia, Lavras, v.27, n.2, p.249-254, 2003.

21. Schwan-Estrada, K.R.F.; Stangarlin, J.R.; Cruz, M.E.S. Uso de extratos vegetais no controle de fungos fitopatogênicos. Revista Floresta, Curitiba, v.30, p.129-137, 2000.

22. Stangarlin, J.R.; Schwan-Estrada, K.R.F.; Cruz, M.E.S.; Nozaki, M.H. Plantas medicinais e controle alternativo de fitopatógenos. Biotecnologia Ciência \& Desenvolvimento, Brasília, v.2, n.11, p.16-21, 1999.

23. Venturoso, L.R.; Rangel, M.A.S.; Souza, F.R.; Conus, L.A.; Coleta, Q.P. Efeito de extratos vegetais e fungicida na qualidade fisiológica de sementes de soja. Fitopatologia Brasileira, Brasília, v.32, supl., p.161, 2007.

24. Viegas, E.C.; Soares, A.; Carmo, M.G.F.; Rossetto, C.A.V. Toxicidade de óleos essenciais de alho e casca de canela contra fungos do grupo Aspergillus flavus. Horticultura Brasileira, Brasília, v.23, n.4, p.915-919, 2005.

25. Wang, S.; Wang, X.; Liu, J.; Cao, K. Screening of Chinese herbs for the fungitoxicity against Phytophthora infestans. Journal of Agricultural University of Hebei, Hebei, v.24, p.101-107, 2001 .

26. Wilson, C.L.; Solar, J.M.; El Ghaouth, A.; Wisniewski, M.E. Rapid evaluation of plant extracts and essential oils for antifungal activity against Botrytis cinerea. Plant Disease, St. Paul, v.81, n.2, p.204-210, 1997. 